А. В. Булашенко ${ }^{1}$, С.І. Пільтяй ${ }^{1}$, І.В. Забегалов ${ }^{2}$

\title{
МЕТОДИ АНАЛІЗУ НАУКОВИХ ПУБЛІКАЦІЙ
}

\author{
${ }^{1}$ Національний технічний університет України «Київський політехнічний інститут ім. \\ Ігоря Сікорського»; \\ ${ }^{2}$ Шосткинський фаховий коледж ім. Івана Кожедуба Сумського державного Університету
}

\begin{abstract}
Анотація
Запропоновано результати дослідження щзодо наукових публікацій у різноманітних наукових журналах та базах.
\end{abstract}

Ключові слова: публікація, стаття, теза, мета дослідження.

\section{Abstract}

The results of research on scientific publications in various scientific journals and databases are offered.

Keywords: publication, article, thesis, research purpose.

\section{Вступ}

Останні часом у зв'язку із поглибленими інтеграційними процесами до Європейської наукової спільноти, посилилися вимоги до українських науковців. Для оцінювання наукової діяльності наукових працівників використовуються кількісні оцінки за допомогою публікацій у наукових базах Google Scholor, Scopus та Web of Science. Це дасть можливість ранжувати показники наукової спільноти. Отже, передбачається, що таке оцінювання слугуватиме збільшенню відсотка публікації українських вчених у світі.

Оцінка наукових публікацій за допомогою сучасних науко метричних баз даних не враховує незалежну експертну оцінку результатів світової науки, специфіку навчальної дисципліни, характер колаборації. Колаборація визначається кількістю вчених, що займаються написанням роботи. Також така кількісна оцінка не враховує рівня журналу, в якому була опублікована наукова стаття. Це призводить до неправильної оцінки рівня наукової діяльності науко-педагогічних кадрів у навчальних закладах освіти.

В результаті виникає ринок фальшивих публікацій у журналах, що видають роботи за на комерційній основі без відповідного рецензування. В результаті трапляються такі випадки, як захист наукових кандидатських дисертацій людьми, які їх не писали. Велика кількість таких журналів знаходиться у розвиваючихся країнах. Тому необхідно користуватися перевіреними та якісними науковими журналами, що входять у наукометричні бази Scopus та Web of Science.

\section{Результати дослідження}

Найпоширенішим методом перевірки кількості наукових публікацій у вчених є база Google Scholor. Ця база дає можливість здійснювати пошук наукових публікацій у мережі Інтернет. Крім того, вона містить данні більшості рецензованих наукових журналів західних, українських та російських. 


\section{Google}

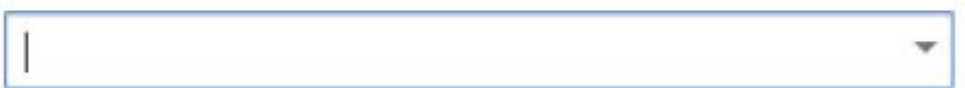

Рис. 1

Приклади наукових показників вчених наведені на рис. 2. та рис. 3.

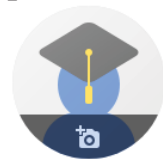

Андрей Булашенко / Andrew Bulashenko/ Булашенко А.В./ А.В. Булашенко/ A.V. Bulashenko ,

НТУу "КПИ"

Подтвержден адрес электронной почты в домене крі.uа - Главная страница Радиоэлектроника

HАЗВАНИЕ

$\uplus \quad \vdots$

Waveguide iris polarizers for Ku-band satellite antenna feeds SI Piltyay, AV Bulashenko, IV Demchenko

Optimization of a polarizer based on a square waveguide with irises AV Bulashenko, SI Piltyay, IV Demchenko
Science-Based Technologies 47 (3), $287-297$

Compact polarizers for satellite information systems

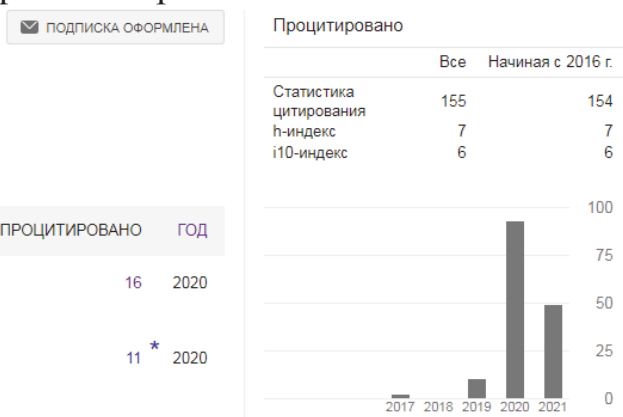

Рис. 2

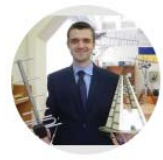

Stepan Piltyay / Степан Пільтяй / Степан Пильтяй

National Technical University of Ukraine "Igor Sikorsky Kyiv Polytechnic Institute"

Подтвержден адрес электронной почты в домене крі.uа

Антени Polarizer Electromagnetic Simulation Microwave Engineering Waveguide Components

НАЗВАНИЕ

Electrodyna technique

Radioelectronics and Communications Systems 55 (5), 191-203

High performance extended C-band $3.4-4.8 \mathrm{GHz}$ dual circular polarization feed system

SI Piltyay

Eigenmodes of coaxial quad-ridged waveguides. Theory
ПРОЦИТИРОВАНО ГОД

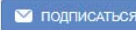

Процитировано

ПPOCMOTPETЬ BCE Все Начиная с 2016 r

Статистика

цитировани
h-индекс

h-индекс

396

396
14

$\begin{array}{ll}14 & 13 \\ 19 & 19\end{array}$

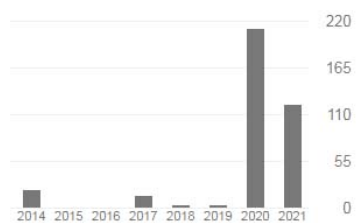

Рис. 3

Видно, що статистичні показники бази $є$ h-індекс та i10-індекс. Перший показник $\epsilon$ індекс Хірша, а другий показник $є$ показник для робіт, що мають мінімум по 10 цитувань

Провідне місце займає науко метрична база Scopus. Вона працює з 2004 року. Загальна кількість рецензованих журналів складає майже 25 тисяч. Саме головне, що статті якісно рецензуються фахівцями і вони вважаються якісними. Для зручності користування групи статей були розбиті на три основні групи, що зведені у таблицю 1.

Таблиця 1. Розподіл за областями у базі Scopus

\begin{tabular}{|c|l|c|}
\hline \multicolumn{1}{|c|}{ Ном } & Назва напряму & Відсоток \\
\hline 1 & Технічні та природничі науки & $41 \%$ \\
\hline 2 & Соціальні та гуманітарні & $33 \%$ \\
\hline 3 & Медичні та фізичні науки & $26 \%$ \\
\hline
\end{tabular}


База Scopus має зручний інтерфейс для користування та зручний поділ на розділи матеріалів. Всього існує 27 розділів за тематиками. Позитивною особливістю цієї бази є наявність великої кількості журналів із відкритим доступом. До цієї бази входить значна кількість українських журналів. На сьогодні їх кількість становить біля 130. Більш того, матеріали весь час оновлюються. Крім того, якщо журнал не відповідає високим вимогам якості, то його виключають із бази. База різноманітні іноземні мови, окрім англійської.

Наукометрична база Web of Science виникла значно раніше від бази Scopus. База містить майже 34 тис. наукових журналів. Акцент зосереджується переважно на природничих та технічних науках. База має зручні інструменти для пошуку та навігації. База охоплює велику кількість країн із різних континентів. В базі Web of Science значно часто використовується англійська мова. Літературні джерела на матеріали, що видані українською або російською мовами не враховуються.

Кожна база має свої науко метричні показники. В базі Scopus оцінка наукових публікацій здійснюється за допомоги індекса Хірша, а у базі Web of Science наукові публікації оцінюються за допомогою імпакт-факторів. Ці показники визначають рівень цитування наукових публікацій.

Журнали по природничім, технічним та соціальним наукам поділені на 4 набори квартилів залежно від того як активно статті у цих журналах цитуються таблиця 2. Гуманітарні журнали по квартилям не ранжуються. Найбільш авторитетні журнали належать зазвичай до перших двох квартилів - Q1 та Q2.

Таблиця 2. Квартилі журналів

\begin{tabular}{|c|l|}
\hline \multicolumn{1}{|c|}{ Квартил } & Характеристика квартилю \\
\hline Q1 & Найвищий квартиль журналу \\
\hline Q2 & Середній квартиль журналу \\
\hline Q3 & Середній квартиль журналу \\
\hline Q4 & Найнижчій квартиль журналу \\
\hline
\end{tabular}

Індекс Хірша $\mathrm{h} \epsilon$ наукометричним показником, що був запропонований у 2005 році американським фізиком Хорхе Хіршем університету Сан-Дієго, Каліфорнія. Цей індекс поєднує кількість публікацій науковця та кількість цитувань цих публікацій. Вчений має індекс Хірша $\mathrm{h}$, якщо $\mathrm{h}$ із його $\mathrm{N}$ статей цитуються мінімум h разів кожна. А інші статті $(\mathrm{N}-\mathrm{h})$ цитуються менше, ніж h разів кожна. Наприклад, індекс Хірша $\mathrm{h}=4$ означає, що вченим було видано не менше 4 роботи, кожна з яких була процитована 4 рази (рис. 4).

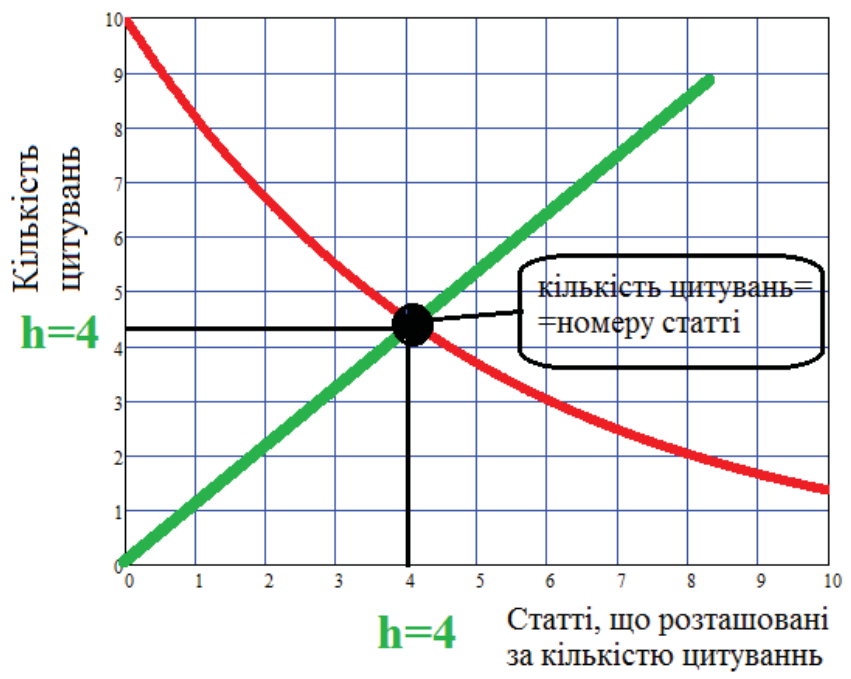

Рис. 4 
Індекс Хірша є кількісна оцінка продуктивності вченого за весь період наукової діяльності. Також індекс Хірша можна визначити із використання безкоштовних баз даних в Інтернеті, наприклад за допомогою Google Scholar. Але не слід забувати, що ця база є менш точною робіт.

Базою Scopus двічі на рік оприлюднюються два «імпакт-фактори»: Scimago Journal Rank (SJR) та Source Normalized impact per paper (SNIP). Перший з них враховує наукову сферу (предметне поле) журналу, його репутацію і якість, тож SJR показує не лише кількість цитувань статей, але й наукову цінність журналу, з якого отримано цитати. Другий полягає в оцінюванні цитат на основі їх загальної кількості у певній предметній сфері. Вплив однієї цитати у сфері, де цитати трапляються рідше, вважається більш значущим.

У таблиці 3 на поточний момент 29.04.2021 наведені індекси SNIP деяких журналів, що входять в базу Scopus.

\begin{tabular}{|c|l|}
\hline SNIP & \multicolumn{1}{|c|}{ Назва журналу } \\
\hline 0.506 & Radioelectronics and Communications Systems \\
\hline 1.337 & CEAS Space Journal \\
\hline 0.440 & Telecommunications and Radio Engineering \\
\hline 0.425 & Journal of Nano- and Electronic Physics \\
\hline
\end{tabular}

У таблиці 4 наведені українські журнали із бази WoS (29.04.2021).

Таблиця 4. Журналі із бази WoS

\begin{tabular}{|c|l|l|}
\hline № & \multicolumn{4}{|c|}{ Назва журналу } \\
\hline 1 & Radio Electronics, Computer Science, Control \\
\hline 2 & Space science and technology & \\
\hline 3 & $\begin{array}{c}\text { Visnyk NTUU KPI Seriia } \\
\text { Radioaparatobuduvannia }\end{array}$ & Radiotekhnika, \\
\hline
\end{tabular}

Приклад показників Scopus окремого довільного західного науковця наведена на рис. 5 (на дату 29.04.2020).

\section{Обзор показателей Документ и тенденции цитирования}

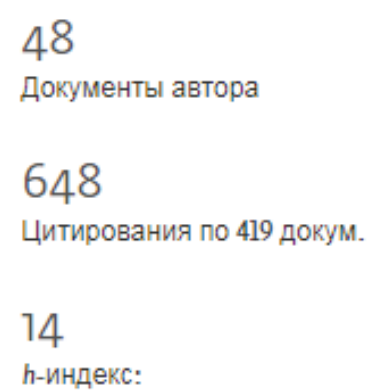

h-индекс:

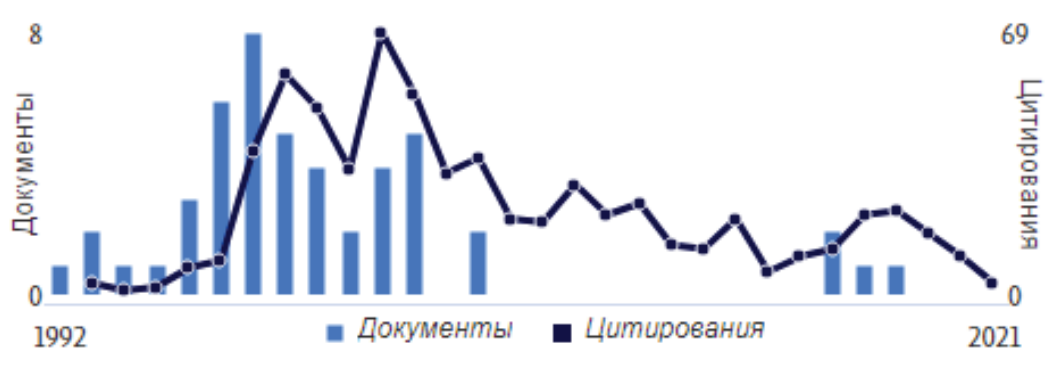

Рис. 5

Приклад показників Scopus доцента Степан Пільтяя наведені на рис. 6 (на дату 29.04.2020). 


\section{Обзор показателей Документ и тенденции цитирования}

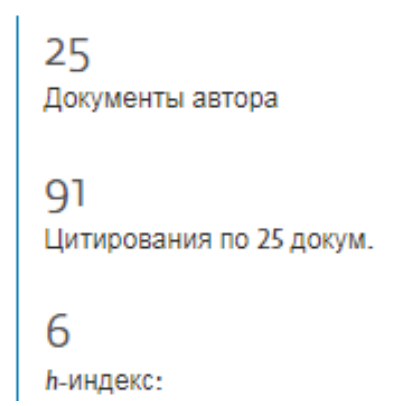

h-индекс:

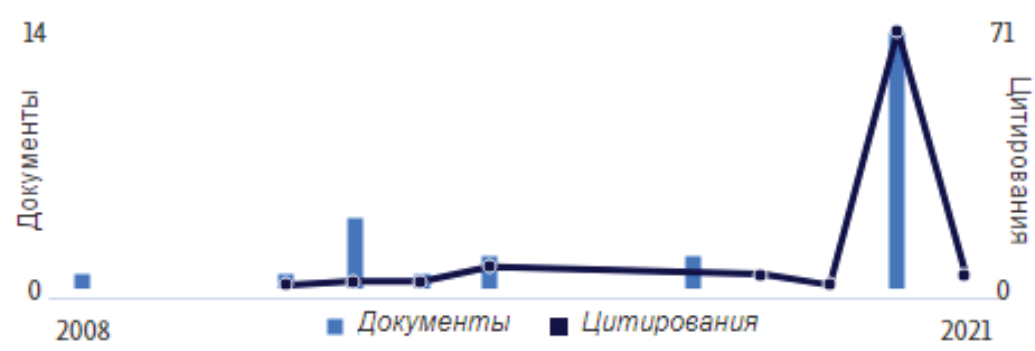

Рис. 6

Приклади нових робіт авторів, що входять у наукометричну базу Web of Science наведені [1-6], а приклади робіт, що входять до науко метричної бази Scopus наведені у [7-32] та базу Google Scholor [33-47].

\section{Висновки}

Таким чином, наукові бази Google Scholor, Scopus та Web of Science дають можливість оцінювати наукову діяльність наукових працівників за допомогою комплексного коефіцієнту індексу Хірша, що здійснює кількісну (кількість публікацій науковця) та якісну (кількість цитувань публікацій науковця) оцінку діяльності.

\section{СПИСОК ВИКОРИСТАНОЇ ЛІТЕРАТУРИ}

1. Piltyay S.I. Numerical performance of FEM and FDTD methods for the simulation of waveguide polarizers / S.I. Piltyay, A.V. Bulashenko, Y.Y. Herhil // Visnyk NTUU KPI Seriia - Radiotekhnika, Radioaparatobuduvannia. - 2021. - Vol. 84, pp. 11-21 (in Ukrainian). http://doi.org/10.20535/RADAP.2020.84.11-21.

2. Bulashenko A.V. Equivalent microwave circuit technique for waveguide iris polarizers development / A.V. Bulashenko, S.I. Piltyay // Visnyk NTUU KPI Seriia - Radiotekhnika, Radioaparatobuduvannia. $\quad-\quad 2020$. $\quad$ - Vol. $83 . \quad-\quad$ pp. 17-28. http://doi.org/10.20535/RADAP.2020.83.17-28.

3. Bulashenko A.V. Evaluation of D2D Communications in 5G networks / A.V. Bulashenko // Visnyk NTUU KPI Seriia - Radiotekhnika, Radioaparatobuduvannia. - 2020. - Vol. 81. pp. 21-29. (in Ukrainian). http://doi.org/10.20535/RADAP.2020.81.21-29.

4. Bulashenko A.V. Combined criterion for the choice of routing based on D2D technology / A.V. Bulashenko // Radio Electronics, Computer Science, Control. - 2021. - Vol. 1. - pp. 7 13. (in Ukrainian). http://doi.org/10.15588/1607-3274-2021-1-1.

5. Piltyay S.I. Enhanced C-band coaxial orthomode transducer / S.I. Piltyay // Visnyk NTUU KPI Seriia - Radiotekhnika, Radioaparatobuduvannia. - 2014. - Vol. 58. - pp. 27-34. http://doi.org/10.20535/RADAP.2014.58.27-34.

6. Dubrovka F.F. Eigenmodes analysis of sectoral coaxial ridged waveguides by transverse field-mathing technique. Part 1. Theory. / F.F. Dubrovka, S.I. Piltyay // Visnyk NTUU KPI Seriia - Radiotekhnika, Radioaparatobuduvannia. - 2013. - Vol. 54. - pp. 13-23. http://doi.org/10.20535/RADAP.2013.54.13-23.

7. Dubrovka F.F. Ultrawideband microwave biconical high-gain antenna for dual-band systems of omnidirectional radio monitoring / F.F. Dubrovka, S.I. Piltyay // Radioelectronics and Communications Systems. - 2020. - Vol. 63, No. 12. - pp. 619-632, 2020. DOI: 10.3103/S0735272720120028. 
8. Piltyay S.I. Waveguide iris polarizers for Ku-band satellite antenna feeds / S.I. Piltyay, A.V. Bulashenko, I.V. Demchenko // Journal of Nano- and Electronic Physics. - 2020. - Vol. 12, No. 5. pp. 05024-1-05024-5. http://doi.org/10.21272/jnep.12(5).05024.

9. Bulashenko A.V. Wave matrix technique for waveguide iris polarizers simulation. Theory / A.V. Bulashenko, S.I. Piltyay, I.V. Demchenko // Journal of Nano- and Electronic Physics. 2020. - Vol. 12, no. 6. - pp. 06026-1-06026-5. DOI: 10.21272/jnep.12(6).06026.

10.Piltyay S.I. Compact Ku-band iris polarizers for satellite telecommunication systems / S.I. Piltyay, O.Yu. Sushko, A.V. Bulashenko, I.V. Demchenko // Telecommunications and Radio Engineering. - 2020. - Vol. 79, no. 19. - pp. 1673-1690. DOI:10.1615/TelecomRadEng.v79.i19.10.

11.Piltyay S.I. Analytical synthesis of waveguide iris polarizers / S.I. Piltyay, A.V. Bulashenko, I.V. Demchenko // Telecommunications and Radio Engineering. - 2020. - Vol. 79, No 18. pp. 1579-1597. http://doi.org/10.1615/TelecomRadEng.v79.i18.10.

12.Bulashenko A.V. Analytical technique for iris polarizers development / A.V. Bulashenko, S.I. Piltyay, I.V. Demchenko // IEEE International Conference on Problems of Infocommunications. Science and Technology, 8-10 October 2020, Kharkiv, Ukraine, pp. 464-469.

13.Piltyay S.I. Compact polarizers for satellite information systems / S.I. Piltyay, A.V. Bulashenko, I.V. Demchenko // IEEE International Conference on Problems of Infocommunications. Science and Technology, 8-10 October 2020, Kharkiv, Ukraine, pp. 350-355.

14. Piltyay S. FDTD and FEM simulation of microwave waveguide polarizers / S. Piltyay, A.Bulashenko, Ye. Herhil, O. Bulashenko // IEEE 2nd Int. Conf. on Advanced Trends in Information Theory, 25-27 November 2020, Kyiv, Ukraine, pp. 132-137. DOI: 10.1109/ATIT50783.2020.9349339.

15.Piltyay S. New tunable iris-post square waveguide polarizers for satellite information systems / S. Piltyay, A. Bulashenko, H. Kushnir, O. Bulashenko // IEEE 2nd International Conference on Advanced Trends in Information Theory, 25-27 November 2020, Kyiv, Ukraine, pp. 342-348. DOI: 10.1109/ATIT50783.2020.9349357.

16. Bulashenko A. Mathematical modeling of iris-post sections for waveguide filters, phase shifters and polarizers / A. Bulashenko, S. Piltyay, Ye. Kalinichenko, O. Bulashenko // IEEE 2nd International Conference on Advanced Trends in Information Theory, 25-27 November 2020, Kyiv, Ukraine, pp. 330-336. DOI: 10.1109/ATIT50783.2020.9349321.

17.Piltyay S.I. Wireless sensor network connectivity in heterogeneous 5G mobile systems / S.I. Piltyay, A.V. Bulashenko, I.V. Demchenko // IEEE International Conference on Problems of Infocommunications. Science and Technology (PIC S\&T), 8-10 October 2020, Kharkiv, Ukraine, pp. 508-513.

18. Bulashenko A.V. Energy efficiency of the D2D direct connection system in $5 G$ networks / A.V. Bulashenko, S.I. Piltyay, I.V. Demchenko // IEEE International Conference on Problems of Infocommunications. Science and Technology, 8-10 October 2020, Kharkiv, Ukraine, pp. 324-329.

19. Bulashenko A. New traffic model of M2M Technology in 5G wireless sensor networks / A. Bulashenko, S. Piltyay, A. Polishchuk, O. Bulashenko // IEEE 2nd International Conference on Advanced Trends in Information Theory, 25-27 November 2020, Kyiv, Ukraine, pp. 125131. http://doi.org/10.1109/ATIT50783.2020.9349305.

20. Dubrovka F. Compact X-band stepped-thickness septum polarizer / F. Dubrovka, S. Piltyay, O. Sushko, R.Dubrovka, M. Lytvyn, S. Lytvyn // IEEE Ukraine Microwave Week, 21-25 Sept. 2020, Kharkiv, Ukraine. DOI: 10.1109/UkrMW49653.2020.9252583.

21. Sushko O. Symmetrically fed 1-10 GHz log-periodic dipole antenna array feed for reflector antennas / O. Sushko, S. Piltyay, F. Dubrovka, // IEEE Ukraine Microwave Week, 21-25 Sept. 2020, Kharkiv, Ukraine. DOI: 10.1109/UkrMW49653.2020.9252778. 
22.Dubrovka F. Circularly Polarised X-band H11- and H21-modes antenna feed for monopulse autotrackung ground station / F. Dubrovka, S. Martunyuk, R. Dubrovka, M. Lytvyn, S. Lytvyn, Yu. Ovsianyk, S. Piltyay, O. Sushko, O. Zakharchenko // IEEE Ukraine Microwave Week, 21-25 Sept. 2020, Kharkiv, Ukraine. DOI: 10.1109/UkrMW49653.2020.9252600.

23. Dubrovka F.F. Optimum septum polarizer design for various fractional bandwidths // F.F. Dubrovka, S.I. Piltyay, R.R. Dubrovka, M.M. Lytvyn, S.M. Lytvyn // Radioelectronics and Communications Systems. - 2020. - Vol. 63, No. 1. - P. 15-23. DOI: https://doi.org/10.3103/S0735272720010021.

24. Dubrovka F. F. Eigenmodes of coaxial quad-ridged waveguides. Numerical results // F.F. Dubrovka, S.I. Piltyay // Radioelectronics and Communications Systems. - 2014. — Vol. 57, № 2. — P. 59-69. DOI: https://doi.org/10.3103/S0735272714020010.

25.Dubrovka F. F. Eigenmodes of sectoral coaxial ridged waveguides // F.F. Dubrovka, S.I. Piltyay // Radioelectronics and Communications Systems. - 2012. - Vol. 55, № 6. - P. 239-247. DOI: https://doi.org/10.3103/S0735272712060015.

26. Naydenko V. Evolution of radiopulses radiated by Hertz's dipole in vacuum / V. Naydenko, S. Piltyay // IEEE International Conference on Mathematical Methods in Electromagnetic, 12 July 2008, Odessa, Ukraine. DOI: 10.1109/MMET.2008.4580972.

27. Dubrovka F. Prediction of eigenmodes cutoff frequencies of sectoral coaxial ridged waveguides / F. Dubrovka, S. Piltyay // IEEE International Conference on Modern Problem of Radio Engineering, Telecommunications and Computer Science, 21-24 February 2012, Lviv, Ukraine.

28. Dubrovka F. A novel wideband coaxial polarizer / F. Dubrovka, S. Piltyay // IX International Conference on Antenna Theory and Techniques, 16-20 Sept. 2013, Odessa, Ukraine, pp. 473-474. DOI: 10.1109/ICATT.2013.6650816.

29. Dubrovka F. Numerically effective basis functions in integral equation technique for sectoral coaxial ridged waveguides / F. Dubrovka, S. Piltyay // XI International Conference on Mathematical Methods in Electromagnetic Theory, 28-30 Aug. 2012, Kharkiv, Ukraine, pp. 492-495. DOI: 10.1109/MMET.2012.6331195.

30. Dubrovka F. A high performance ultrawideband orthomode transducer and dual-polarized quad-ridged horn antenna based on it / F. Dubrovka, S. Piltyay // IEEE International Conference on Antenna Theory and Techniques, 20-23 Sept. 2011, Lviv, Ukraine, pp. 176178. DOI: 10.1109/ICATT.2011.6170737.

31. Dubrovka F. Novel high performance choherent dual-wideband orthomode transducer for coaxial horn feeds / F. Dubrovka, S. Piltyay // XI International Conference on Antenna Theory and Techniques, 24-27 May 2017, Kyiv, Ukraine, pp. 277-280. DOI: 10.1109/ICATT.2017.7972642.

32. Piltyay S.I. High performance extended C-band 3.4-4.8 GHz dual circular polarization feed system / S.I. Piltyay // XI International Conference on Antenna Theory and Techniques, 2427 May 2017, Kyiv, Ukraine, pp. 284-287. DOI: 10.1109/ICATT.2017.7972644.

33. Bulashenko A.V. Optimization of a polarizer based on a square waveguide with irises / A.V. Bulashenko, S.I. Piltyay, I.V. Demchenko // Science-Based Technologies. - 2020. - Vol. 47, No. 3. - pp. 287-297. (in Ukrainian). http://doi.org/10.18372/2310-5461.47.14878.

34.Bulashenko A.V. Waveguide polarizer with three irises for antennas of satellite television systems / A.V. Bulashenko, S.I. Piltyay, H.S. Kushnir, O.V. Bulashenko // Science-Based Technologies. - 2021. - Vol. 49, No. 1. - pp. 39-48. (in Ukrainian). http://doi.org/10.18372/2310-5461.49.15290.

35. Bulashenko A.V. Data upload system using D2D technology in the unlicensed frequency range as part of the 5G communication system / A.V. Bulashenko // Technical Engineering. - 2020. - Vol. 86, No. 2. - pp. 103-107. (in Ukrainian). http://doi.org/10.26642/ten-20202(86)-103-107.

36. Bulashenko A.V. Tunable square waveguide polarizer with irises and posts / A.V. Bulashenko, S.I. Piltyay, Y.I. Kalinichenko, O.V. Bulashenko // Technical Engineering. - 
2020. - Vol. 86, no 2. - pp. 108-116. [In Ukrainian]. DOI: 10.26642/ten-2020-2(86)-108116.

37. Bulashenko A.V. Resource allocation for low-power devices of M2M technology in 5G networks / A.V. Bulashenko // KPI Science news. - 2020. - Vol. 3. - pp. 7-13. (In Ukrainian). http://doi.org/10.20535/kpi-sn.2020.3.203863.

38.Bulashenko A.V. Simulation of compact polarizers for satellite telecommunication systems with the account of irises' thickness / A.V. Bulashenko, S.I. Piltyay, I.V. Demchenko // KPI Science news. - 2021. - Vol. 1. - pp. 25-33. http://doi.org/10.20535/kpi-sn.2021.1.203863.

39. Bulashenko A.V. Compact waveguide polarizer with three antiphase posts / A.V. Bulashenko, S.I. Piltyay, H.S. Kushnir, O.V. Bulashenko // Visnyk VPI. - 2020. - Vol. 5. pp. 97-104. [In Ukrainian]. DOI: 10.31649/1997-9266-2020-151-5-97-104.

40.Piltyay S.I. High performance waveguide polarizer for satellite information systems / S.I. Piltyay, A.V. Bulashenko, Ye.I. Kalinichenko, O.V. Bulashenko // Bulletin of Cherkasy State Technological University. - 2020. - Vol. 4. - pp. 14-26. [In Ukrainian]. DOI: 10.24025/2306-4412.4.2020.217129.

41. Булашенко А.В. Конструкція портативного цифрового мегомметра та вимірювача струму витоку / А.В. Булашенко, І.В. Забегалов // Вісник ВПІ. - 2020. - Вип. 3. - с. 37-42. https://doi.org/10.31649/1997-9266-2020-150-3-37-42.

42. Bulashenko A.V. Compact waveguide polarizer with three antiphase posts / A.V. Bulashenko, S.I. Piltyay, H.S. Kushnir, O.V. Bulashenko // Visnyk VPI. - 2020. - Vol. 5. pp. 97-104. [In Ukrainian]. DOI: 10.31649/1997-9266-2020-151-5-97-104.

43.Piltyay S. Information resources economy in satellite systems based on new microwave polarizers with tunable posts / S. Piltyay, A. Bulashenko, H. Kushnir, O. Bulashenko // Path of Science. - 2020. - Vol. 6, No 11. - pp. 5001-5010. http://doi.org/10.22178/pos.55-1.

44. Bulashenko A.V. Beamforming principels of smart antennas / A.V. Bulashenko // Visnik Sumy State University. Seriia Technical sciences. - 2010. - Vol. 1. - pp. 111-120.

45. Bulashenko A.V. Multibeam arrays on the basis of Rotman lenses / A.V. Bulashenko // Visnyk NTUU KPI Seriia - Radiotekhnika, Radioaparatobuduvannia. - 2010. - Vol. 42. pp. 178-186. http://doi.org/10.20535/RADAP.2010.42.178-186.

46. Булашенко А.В. Живлення антенних решіток на основі лінз Ротмана (огляд) / А.В. Булашенко, Ф.Ф. Дубровка // Вісник Сумського державного університету. Серія Технічні науки. - 2010. - №3, Т.2. - С. 113-120.

47. Dubrovka F. Boundary problem solution for eigenmodes in coaxial quad-ridged waveguides / F. Dubrovka, S. Piltyay // Information and Telecommunication Science. - 2014. - Vol. 5, no. 1. - pp. 48-61. DOI: 10.20535/2411-2976.12014.48-61.

Булашенко Андрій Васильович - ст. викл. кафедри теоретичних основ радіотехніки, Національний технічний університет України «Київський політехнічний інститут ім. Ігоря Сікорського», Київ;

Пільтяй Степан Іванович - к.т.н., доцент кафедри теоретичних основ радіотехніки, Національний технічний університет України «Київський політехнічний інститут імені Ігоря Сікорського», Київ.

Забегалов Ігор Вікторович - викл. електротехнічного відділення, Шосткинський фаховий коледж імені Івана Кожедуба Сумського державного університету, м. Шостка, e-mail: igor_zabegalov@meta.ua.

Bulashenko Andrew V. - senior lecture of the chair of theoretical foundations of radio engineering, National Technical University of Ukraine «Igor Sikorsky Kyiv Polytechnic Institute», Kyiv;

Piltyay Stepan I. - Cand. Sc. (Eng), Assistant Professor of the Department of Theoretical Foundations of Radio Engineering, National Technical University of Ukraine «Igor Sikorsky Kyiv Polytechnic Institute», Kyiv.

Zabegalov Igor V. - lecturer of Electromechanical Department, Ivan Kozhedub Shostka Professional College of Sumy State University, Shostka, Sumy region, e-mail: igor_zabegalov@meta.ua. 